\title{
Parent-Initiated Motivational Climate, Self-Esteem, and Autonomous Motivation in Young Athletes: Testing Propositions from Achievement Goal and Self-Determination Theories
}

\author{
Daniel J. O’Rourke, ${ }^{1}$ Ronald E. Smith, ${ }^{1}$ Frank L. Smoll, ${ }^{1}$ and Sean P. Cumming ${ }^{2}$ \\ ${ }^{1}$ Department of Psychology, University of Washington, Seattle, WA 98195-1525, USA \\ ${ }^{2}$ School of Health, University of Bath, Bath BA2 7AY, UK \\ Correspondence should be addressed to Daniel J. O’Rourke, djo13@uw.edu
}

Received 30 March 2012; Revised 9 July 2012; Accepted 24 July 2012

Academic Editor: Cheryl Dissanayake

Copyright ( 2012 Daniel J. O'Rourke et al. This is an open access article distributed under the Creative Commons Attribution License, which permits unrestricted use, distribution, and reproduction in any medium, provided the original work is properly cited.

\begin{abstract}
Interactions with parents are known to have a significant impact on children's self-esteem. In this study, designed to test propositions derived from Achievement Goal Theory and Self-Determination Theory, we assessed the influence of perceived parent-initiated mastery and ego motivational climates on self-esteem and self-esteem change in competitive youth swimmers over the course of a 32-week sport season. At each of three measurement points (early, mid, and late season), mastery climate scores on the Parent-Initiated Motivational Climate Questionnaire-2 scale were positively related to global self-esteem scores and to a measure of relative motivational autonomy that reflects the intrinsic-extrinsic motivation continuum, whereas ego climate scores were negatively related to self-esteem and autonomy. Longitudinal analyses revealed that early-season mastery climate predicted positive changes in self-esteem over the course of the season, whereas ego climate predicted decreased self-esteem. Consistent with predictions derived from Self-Determination Theory, a meditational analysis revealed that these self-esteem changes were mediated by changes in autonomous motivation.
\end{abstract}

\section{Introduction}

The centrality of the self-concept has been emphasized by many theorists as an object of self-awareness and a determinant of behavior [1-6]. The evaluative aspect of the selfsystem is commonly referred to as self-esteem. Historically, few personality constructs have received greater theoretical and empirical attention than self-esteem. Although selfevaluations may relate to specific areas of experience, such as social, academic, and athletic domains, most theorists also posit a superordinate construct that refers to a generalized sense of self-worth [3, 7]. Global self-esteem is an important indicator of psychological well-being $[2,4,8,9]$.

Developmental factors that influence self-esteem have attracted the attention of both theorists and researchers. Within a variety of settings, interactions with significant others provide important feedback in the form of reflected appraisals, and social comparison processes evoke selfevaluative inferences about one's traits and competencies $[10,11]$. One such domain in which specific personal and reflected evaluations of self-worth can be generated is sport [12-14]. In part, this is because the environmental conditions created by significant others, such as coaches or parents, reinforce specific behaviors in youth athletes that contribute toward attaining psychological well-being $[5,13-$ 16]. In addition, sport exposes athletes to environmental influences that affect motivational processes thought to contribute to well-being and self-esteem $[5,17]$.

The relation between motivation and self-esteem is the focus of the present research. Motivational factors are thought to be critical to the development and maintenance of self-esteem $[14,18]$. Researchers have also suggested that 
the social environment is a main contributor to the quality of motivation and therefore to self-esteem $[4,5,13]$. In this paper, we link self-esteem, and changes in selfesteem, to theoretical concepts drawn from two prominent motivational theories, namely, Achievement Goal Theory and Self-Determination Theory $[4,5,16,19]$.

Achievement Goal Theory (AGT) focuses on how the social environment influences achievement goals and competence evaluations. Although the theory continues to evolve, the key principle in AGT is that individuals vary in their conceptions of what constitutes success. In a task, or mastery conception, success evaluations are self referenced rather than other-referenced, and people view themselves as successful when they give maximal effort, increase their skill level, demonstrate personal mastery, and learn from mistakes. The focus is on personal improvement "become the best you can be" and on enjoyment of the process involved in gaining competencies. In an ego conception, success perceptions are based on social comparison processes, and success perceptions are contingent on "winning" by outperforming others using equal or less effort, often in the service of attaining recognition and status [19-22].

In an achievement situation such as sport, individuals adopt specific conceptions of success and attempt to achieve the success criterion and/or to avoid a failure criterion. Whether an individual is focused on mastery or ego goals in a particular moment is influenced by interacting dispositional and environmental factors. The most important dispositional factor is a general orientation toward mastery or ego-oriented goals (i.e., a mastery orientation or an ego orientation). The environmental factor of importance is the motivational climate, comprised of the communicated values and reinforcement contingencies created by significant others. Corresponding to mastery and ego achievement goal orientations are mastery and ego motivational climates $[18,19]$. A mastery climate reinforces self-referenced improvement, learning from mistakes, effort, and enjoyment, whereas an ego climate rewards outperforming others using the minimal required effort, while punishing mistakes $[19,21$, 22]. Research demonstrates that the motivational climate strengthens its corresponding goal orientation and that modifying the motivational climate can result in shifts in the nature and/or strength of young athletes' goal orientations [23-25].

In general, a mastery climate has more salutary effects than does an ego climate in both academic and athletic settings. These benefits include lower performance anxiety $[23,26]$, higher feelings of competence, greater enjoyment of the activity, and higher intrinsic motivation and effort $[20,27]$. A mastery orientation (particularly in combination with a low ego orientation) is also related to a variety of adaptive achievement behaviors, such as exerting consistent effort, persistence in the face of setbacks, and sustained and improved performance $[19,20,28]$. Researchers have also found that a mastery climate created by teachers and athletic coaches is linked to higher self-esteem, while an ego climate predicts lower self-esteem [14, 18, 28, 29]. Moreover, coach training interventions that promoted a mastery climate have demonstrated a self-esteem enhancing effect on young athletes [30, 31].

Mechanisms whereby a mastery climate influences selfesteem have also been the focus of research. One line of research, inspired by Self Determination Theory [4, 5], has focused on externally controlled versus autonomous aspects of motivation. SDT posits that there are three basic human needs necessary for psychological well-being. These needs include competence (perceived mastery over behavior), relatedness (perceived sense of belonging), and autonomy (perceived sense of self-determination over behavior). According to SDT, behavioral regulation varies from being highly controlled to highly autonomous, and the degree to which motivation is autonomous determines need satisfaction. In particular, the need for autonomy is satisfied to the extent that the locus of motivation is internally rather than externally based [5]. This proposition has received strong empirical support from findings that when behavior is perceived as more self-determined, general well-being is enhanced $[27,29,32-34]$. Of particular significance is the finding that environments that produce greater intrinsic motivation are associated with higher levels of self-esteem $[13,14,17,18,35]$. One such environment, derived from AGT, is a mastery climate $[14,18]$. However, López-Walle and colleagues [18] and Standage and Gillison [14] found that although a coach-initiated mastery climate predicts higher self-esteem in athletes, this effect appears to be mediated by of the athlete's level of intrinsic motivation for the activity. The researchers concluded that the encouragement of more intrinsic forms of motivation is one mechanism through which a mastery climate helps to foster high self-worth. This makes conceptual sense given that autonomous motivation should help engender a sense of selfworth compared to conditions in which behavior is dictated by external and more controlled outcomes.

Combining concepts from AGT and SDT provides a theoretical and empirically supported framework in which to study self-esteem in young athletes. SDT predicts that an autonomy-supportive environment fosters self-esteem through increasing levels of internally-motivated behavior. From an AGT perspective, previous research $[14,18]$ suggests that one way in which a mastery climate is conducive to higher self-esteem is by promoting autonomous forms of motivation that enhance well-being, including self-esteem.

The present study builds upon previous results in three major ways. First, all previous research has focused on the motivational climate initiated within the athletic setting by the coach. However, parents also create a parallel motivational climate to which their children are exposed. To this point, the role of parent-initiated motivational climate has received far less attention, even though parents are acknowledged as an essential contributor to well-being and motivational development in children [36-39]. In addition, youth athletes typically experience extensive parental exposure to achievement-related values and across a broad range of settings. In this study, we therefore focus on the athlete-perceived parent-initiated motivational climate and its influence on both self-esteem and autonomy. 
A second focus of this study is on potential changes in self-esteem as a function of the motivational climate. To this point, research linking motivational climate and selfesteem has been cross-sectional in nature. In this study, we examine the role of perceived parent-initiated motivational climate upon youth athletes' self-esteem longitudinally over the course of a 32-week sport season. Drawing upon previous findings derived from AGT and SDT, we also examined the possible meditational role of climate-linked autonomy change to changes in self-esteem within this longitudinal framework. Specifically, we tested the mediational model shown in Figure 1. Previous research $[14,18]$ has focused on the role of intrinsic motivation. We build upon this by considering the relative strength of autonomous (intrinsically and extrinsically regulated) motivation, thereby addressing the dimensional approach of SDT and building on its theoretical and empirical foundations. Finally, the sample we studied is younger than most previous samples that have examined parent-initiated motivational climate, falling within a late childhood-early adolescence age range in which, according to theorists, self-esteem is more malleable and strongly influenced by relevant experiences and selfevaluations $[3,6,8]$.

This study tests three hypotheses involving constructs derived from AGT and SDT. First, we hypothesize that athlete-perceived behaviors that define a parent-initiated mastery climate will be positively related to athletes' selfesteem in cross-sectional analyses conducted over the course of a sport season, whereas an ego climate will exhibit a negative relation with self-esteem. Second, we believe that if the motivational climate is influential over this period of time, we would expect a mastery climate to promote positive changes in self-esteem and that an ego climate will not enhance and may even decrease self-esteem. Finally, based on previous findings that autonomous motivation enhances well-being, including self-esteem, by enhancing one's sense of personal control and self-determination [4], we hypothesize that changes in autonomous motivation for participation will contribute to (i.e., at least partially mediate) the relation between perceived motivational climate and athletes' self-esteem change.

\section{Method}

2.1. Participants. Participants were 304 athletes (123 boys and 181 girls, $M$ age $=11.88, \mathrm{SD}=1.34$, age range $=9$ 14 years) from three elite swim clubs in a regional swimming program associated with USA Swimming. The ethnic membership was 71.0\% Caucasian, 13.2\% Asian, and 15.8\% representing other ancestries. On average, athletes were club members for $3.30(\mathrm{SD}=2.03)$ years and had engaged in competitive swimming since age $7(M=7.27, \mathrm{SD}=$ 2.22). Competitive swimming occurred on a year-round basis, comprising daily weekday practices with competitive meets on many weekends. The competitive season was most intense from August to May, and athletes were coached by professionals employed by the clubs. The attrition rate was $0.03 \%$ from Time 1 to Time 2, and $22.74 \%$ from Time 2 to Time 3 because of lowered attendance at practices by season

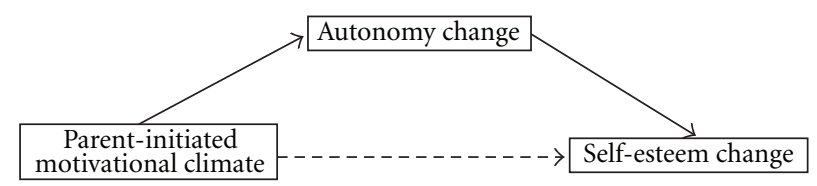

Figure 1: The proposed mediational model of the current study. Parent-initiated motivational climate is hypothesized to predict selfesteem change from early to late season. This relation is thought to be mediated by autonomy change from early to late season.

end. Athletes who failed to provide data at Time 3 did not differ significantly at Times 1 or 2 from those who did.

\subsection{Measures}

2.2.1. Parent-Initiated Motivational Climate. The ParentInitiated Motivational Climate Questionnaire-2 (PIMCQ2) was used to assess children's perceptions of the parentinitiated motivational climate. The PIMCQ-2 [39] normally provides scores on three subscales, one reflecting a mastery orientation (the learning and enjoyment-emphasis subscale) and two reflecting ego orientation (success-without-effort and worry-conducive behaviors subscales). Before using the scale in its original form, we assessed its factorial validity for our sample. Our data, based in part on an age group younger than that in which the scale was originally developed, failed to produce the three-factor solution reported by Duda and Whitehead [40]. Instead, in this younger sample, we found a 2-factor structure that was consistent with the DudaWhitehead mastery-related factor (containing learning and enjoyment items) and a single ego factor (containing successwithout-effort and worry-inducing items), with eigenvalues exceeding 1.00. Nine items with factor loadings exceeding .40 comprised the parent-initiated mastery climate scale (e.g., "is most satisfied when I learn something new") and nine items with similar loadings assessed ego climate (e.g., "looks satisfied when I win without effort"). Children responded to the stem "I feel that my mother/father/guardian..." on a 4point scale ranging from 1 (strongly disagree) to 4 (strongly agree) for each item.

Internal consistency was acceptable at all three time points (Cronbach's alpha $=.76$ to .79 for the mastery climate scale and .83 to .85 for the ego climate scale). A FleschKincaid readability analysis placed the reading level of the scale at grade 5.5 (approximately age 11). Given the relatively high socioeconomic and educational characteristics of the current sample, we judged the scale appropriate for our use.

2.2.2. Self-Esteem. Global self-esteem was measured using the Washington Self-Description Questionnaire (WSDQ). The WSDQ [31, 41] consists of 14 descriptive statements, each of which is rated on a 4-point scale ranging from 1 (not like me) to 4 (very much like me). As recommended by Wylie [6], all of the items are global evaluative in nature rather than focused on particular domains of competence, such as academics, sports, or social competencies. In this respect, the WSDQ resembles Rosenberg's (1979) scale [10], but the items are more simply worded to enhance children's 
comprehension. Six of the items refer to positive attributes (e.g., "I feel proud of myself"), whereas eight items relate to negative self-valuations (e.g., "I often wish I were someone else"). The scale is designed to provide a maximum range of scores (14 to 56) with a relatively small number of items. In previous research, the scale has been found to have high internal consistency (.80 to .86), good test-retest reliability in children of this age range, and validity as both a moderator and outcome variable $[31,41]$. In the present sample, Cronbach's alpha exceeded .82 at all time periods. As in previous research with this age group, the WSDQ exhibited a low correlation $(+.17)$ with the Children's Social Desirability Scale [42] in this sample, supporting its discriminant validity.

2.2.3. Autonomy. Swimming-related motivation was measured using an adaptation of the Self-Regulation Scale [34] used by Gagné et al. [43]. This scale consisted of 15 items designed to measure a continuum that includes intrinsic motivation, three types of extrinsic motivation that vary in terms of the degree to which they are congruent with and emanate from the self, plus amotivation. Items relevant to each type of motivation are answered in response to the question: "why do you swim?" Responses are made on a rating scale that extends from 1 (not true at all) to 7 (very true). Three items each assesses intrinsic motivation (e.g., "For the pleasure I feel when I swim") identified regulation (e.g., "It is a good way to get exercise") and introjected regulation (e.g., "I would feel bad about myself if I was not taking time to swim"), external regulation (e.g., "My parents or other family members give me money or other rewards when I do it"), and amotivation (e.g., "It is not clear to me anymore; I do not really think swimming is my sport").

In addition to providing scores on each of the subscales, a relative index of self-determined motivation, or autonomy, has been developed by Ryan and coworkers [43, 44]. This index is based on the proposition that actions governed by identified regulation share some noteworthy features of internalization and self-acceptance with intrinsic motivation. In contrast, introjected regulation involves self-esteem maintenance rather than intrinsic task involvement and is conceptually more similar to extrinsic motivation based on external contingencies. Using per item means, the relative autonomy index (RAI) is derived from the SMS subscales using the following mean-per-item formula: 2 (intrinsic motivation) +1 (identified regulation) -1 (introjected regulation) - 2 (external regulation). Internal consistency coefficients for the 3-item motivational subscales ranged from .62 (identified regulation) to .75 (intrinsic motivation) and averaged .69. These reliabilities are similar to those reported by Gagné and colleagues [43] and Grolnick and Ryan [44]. This single index also lent itself well to the planned mediational analysis of autonomous motivation on the relation between motivational climate and self-esteem change.

2.3. Procedure. Over a 32-week period, we administered the measures described above to groups of swimmers on three occasions (early, mid and late season). We obtained parental/guardian consent and athlete assent for all participants, trained research assistants, and conducted the data collection sessions at the respective swim clubs. Coaches were informed that our research was intended to measure influences upon athletes' attitudes and outcomes in youth sport participation, while athletes were told that the research was intended to promote greater understanding about their experiences in sport. To enhance the likelihood of valid and complete data, we told athletes prior to the season that they would be given a $\$ 4$ Baskin-Robbins ice cream gift certificate after each of the three questionnaire sessions to provide a reward for their responding to each questionnaire item carefully and accurately.

\section{Results}

Descriptive statistics and Pearson product moment correlations among the motivational climate, self-esteem, and athlete motivational variables at each time period are presented in Table 1. As theory suggests mastery and ego climate scores, which reflect behaviors that can covary in various combinations, were negatively correlated $(-.36$ at Time $1,-.40$ at Time 2, and -.42 at Time 3), but these correlations are not nearly as high as those reported in older athlete samples (e.g., White, 1998 [39]). Mastery climate scores averaged lower temporal stability (.55) across the season than did ego climate scores (.69) over the three 16-week measurement periods, but all stability coefficients were highly significant. The relative autonomy index demonstrated reasonably good temporal stability for the three measurement periods, averaging .69 overall.

Our analyses addressed several related empirical questions. First, we assessed the cross-sectional relations between perceived parent-initiated motivational climate and selfesteem at each of the three measurement points, allowing us to determine the replicability of relations across the season. Second, in a prospective longitudinal analysis, we examined the extent to which early-season motivational climate predicted changes in self-esteem over the course of the season after controlling for early-season self-esteem. Finally, we conducted a meditational analysis to assess the potential role of changes in autonomy as a mediator of selfesteem change over the course of the season.

We first carried out a cross-sectional analysis of the relations between motivational climate and self-esteem over the course of the season. Correlational analyses, shown in Table 1, revealed a clear pattern of relations between perceived parental motivational climate and self-esteem at all three time points. As predicted on the basis of previous research, mastery climate scores were positively associated with self-esteem scores, whereas ego climate scores were negatively correlated with self-esteem. Although autonomous motivation was studied as a possible mediator, it is worth noting that the relative autonomy index was correlated not only with self-esteem but also with motivational climate in a theoretically predicted manner. On average across the time periods, RAI correlated positively with mastery climate scores (mean $r=.43, P<.01$ ) and negatively with ego climate scores (mean $r=-.43, P<.01$ ). 
TABLE 1: Descriptive statistics and bivariate correlations among motivational climate, self-esteem, and autonomy scores at each measurement period.

\begin{tabular}{|c|c|c|c|c|c|c|c|}
\hline & Self-esteem $^{1}$ & Self-esteem $^{2}$ & Self-esteem $^{3}$ & Autonomy $^{1}$ & Autonomy $^{2}$ & Autonomy $^{3}$ & Mean (SD) \\
\hline Mastery climate $^{1}$ & $.31^{*}$ & $.28^{*}$ & $.28^{*}$ & $.36^{*}$ & $.38^{*}$ & $.37^{*}$ & $30.31(3.61)$ \\
\hline Mastery climate ${ }^{2}$ & $.31^{*}$ & $.36^{*}$ & $.36^{*}$ & $.32 *$ & $.42^{*}$ & $.43^{*}$ & $30.15(3.65)$ \\
\hline Mastery climate ${ }^{3}$ & $.26^{*}$ & $.34^{*}$ & $.45^{*}$ & $.26^{*}$ & $.24^{*}$ & $.41^{*}$ & $30.43(3.81)$ \\
\hline Ego climate $^{1}$ & $-.37^{*}$ & $-.38^{*}$ & $-.36^{*}$ & $-.41^{*}$ & $-.43^{*}$ & $-.43^{*}$ & $15.99(4.94)$ \\
\hline Ego climate $^{2}$ & $-.31^{*}$ & $-.40^{*}$ & $-.37^{*}$ & $-.35^{*}$ & $-.42 *$ & $-.42^{*}$ & $15.12(4.87)$ \\
\hline Ego climate $^{3}$ & $-.20^{*}$ & $-.29^{*}$ & $-.40^{*}$ & $-.28^{*}$ & $-.33^{*}$ & $-.48^{*}$ & $14.90(4.78)$ \\
\hline Self-esteem ${ }^{1}$ & - & $.69^{*}$ & $.55^{*}$ & $.34^{*}$ & $.23^{*}$ & $.34^{*}$ & $46.58(6.14)$ \\
\hline Self-esteem ${ }^{2}$ & - & - & $.82^{*}$ & $.40^{*}$ & $.39^{*}$ & $.33^{*}$ & $46.53(7.26)$ \\
\hline Self-esteem ${ }^{3}$ & - & - & - & $.34^{*}$ & $.31^{*}$ & $.40^{*}$ & $47.03(7.00)$ \\
\hline Autonomy ${ }^{1}$ & $.34^{*}$ & $.40^{*}$ & $.34^{*}$ & - & $.68^{*}$ & $.62^{*}$ & $20.72(13.80)$ \\
\hline Autonomy ${ }^{2}$ & $.23^{*}$ & $.39^{*}$ & $.33^{*}$ & - & - & $.76^{*}$ & $20.81(13.80)$ \\
\hline Autonomy ${ }^{3}$ & $.24^{*}$ & $.31^{*}$ & $.40^{*}$ & - & - & - & $23.69(13.43)$ \\
\hline
\end{tabular}

${ }^{*} P<.01,{ }^{1}$ early season, ${ }^{2}$ mid season, ${ }^{3}$ late season.

To assess the combined role of mastery and ego scores, we computed regression analyses in which the two scores predicted self-esteem at the same time period. At all three time points, we obtained significant effects for perceived parent-initiated motivational climate, $F(2,301)=31.64$, $R=.42, B_{\text {mastery }}=.35, B_{\text {ego }}=-.37, P<.01, F(2,294)=$ $38.62, R=46, B_{\text {mastery }}=.48, B_{\text {ego }}=-.45, P<.01$, and $F(2,226)=37.30, R=.50, B_{\text {mastery }}=.64, B_{\text {ego }}=-.36, P<$ .01 , respectively. Thus, the combined motivational climate predictor variables accounted for $17 \%$ to $25 \%$ of the selfesteem variance.

We then examined relations between motivational climate and self-esteem change over the course of the season. As the correlations in Table 1 indicate, motivational climate exhibited a moderate level of consistency between the measurement intervals, with the relations being somewhat higher (.60 to .80) for the ego climate scores than for the mastery climate scores (.50 to .60). Given the relative stability of climate scores, we used Time 1 motivational climate scores to predict changes in self-esteem scores across the season from Time 1 to Time 3 . In these analyses, we took into account the fact that the individual climate scores do not capture the potential interactions between perceived mastery- and ego-oriented parental behaviors. The moderate correlation between the two scales (around -.40) indicates that the motivational climate behaviors do not represent ends of a bipolar continuum. Rather, it is not only possible, but virtually certain that parents can exhibit both types of behaviors to varying degrees. To take into account the combined roles of mastery and ego climate behaviors, we therefore utilized a regression-based approach recommended by J. B. Cohen and P. Cohen [45] and Aiken and West [46] to clarify relations between continuous predictor and criterion variables. This procedure involves using an empirically derived regression equation to calculate predicted criterion variable scores (in this case, Time 3 minus Time 1 self-esteem change scores) within the multidimensional space representing theoretically relevant combinations of predictor variable (in this case, climate) scores. Using SPSS version 18.0, we first conducted a linear regression analysis, entering Time 1 mastery and ego climate scores as predictor variables and self-esteem change as the outcome variable. To capture four theoretically relevant patterns of mastery and climate scores, we then entered into the regression equation climate scores that were (a) high $(+1 \mathrm{SD})$ above the mastery climate mean and low ( $-1 \mathrm{SD}$ ) below the ego climate mean (i.e., high mastery, low ego), (b) high mastery and mean-level ego climate scores, (c) high ego and mean-level mastery climate scores, and (d) high ego and low mastery climate scores. This procedure generated predicted self-esteem change scores for four different theoretically relevant patterns of mastery and ego behaviors, allowing a conservative assessment of the effects of each motivational climate combination.

Figure 2 shows the predicted self-esteem change scores. Mastery climate scores at Time 1 predicted a modest increase in self-esteem over the course of the season, particularly in combination with low ego climate scores. Conversely, high ego scores (particularly when combined with low mastery scores) were associated with reductions in self-esteem, particularly in combination with low levels of masteryoriented parental behaviors. Although the mean changes were modest in magnitude, some athletes, however, exhibited notable changes across the season. The SD of self-esteem change scores exhibited by the athletes ( 5.94 points) spanned nearly 1 SD in the Time 1 self-esteem distribution.

To test the significance of the longitudinal pattern represented in Figure 1, we carried out a hierarchical regression analysis in which we used Time 1 motivational climate scores to predict self-esteem change scores between Time 1 and Time 3, controlling for Time 1 self-esteem level. In a hierarchical regression model, we first entered Time 1 self-esteem as a control variable then entered the two motivational climate scores at step 2. Not surprisingly, given its relative stability, Time 1 self-esteem was a significant predictor of self-esteem change, $F$ change $(1,214)=31.08, P<.001$, $R^{2}=.127$. The motivational climate scores accounted for a 


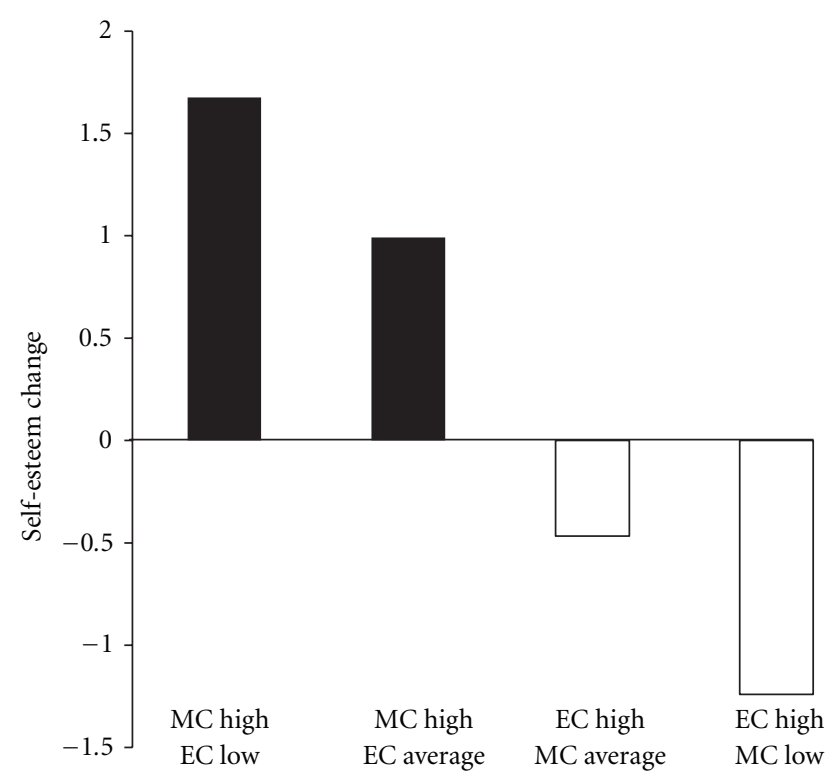

Figure 2: Predicted self-esteem change from early to late season, controlling for early season self-esteem, as a function of early season parent-initated motivational climate. $\mathrm{MC}=$ mastery climate, $\mathrm{EC}=$ ego climate.

modest but statistically significant increment in self-esteem change variance, $F$ change $(2,212)=4.12, R^{2}=.033, P<.02$, $b_{\text {mastery }}=.21, b_{\text {ego }}=-.14$.

A final analysis assessed the possibility that motivational climate-related changes in self-esteem were, at least in part, mediated by changes in autonomy (controlled versus autonomous motivation), as shown by López-Walle and colleagues [18] and Standage and Gillison [14], who studied coach-initiated motivational climate. Mediation requires that (a) motivational climate be related to self-esteem change (already established in previous analyses), (b) that autonomy change be significantly related to both the predictor (motivational climate) and criterion (self-esteem change) variables, and (c) the relation between motivational climate and selfesteem change is attenuated or eliminated when autonomy change is statistically controlled. Accordingly, using the meditational analytic strategy described by Baron and Kenny [47], we first regressed self-esteem change on motivational climate, controlling for self-esteem scores at Time 1 , in the analysis described above, revealing a significant predictive relation. Second, we regressed Time 1-Time 3 autonomy change on motivational climate scores, controlling for autonomy level at Time 1 in a hierarchical model. This analysis revealed a significant relation, $F$ change $(2,221)=12.51, R^{2}$ change $=.08, b_{\text {mastery }}=.45, b_{\text {ego }}=-.59, P<.001$. Third, we regressed self-esteem change on autonomy change, controlling for Time 1 autonomy and Time 1 motivational climate, again revealing a significant relation, $F$ change $(1,212)=$ $10.25, R^{2}$ change $=.046, B_{\text {mastery }}=.06, B_{\text {ego }}=-.09, P<$ .01. Finally, to test mediation, we regressed self-esteem change on Time 1 motivational climate while controlling for autonomy change. This step eliminated the previously obtained significant relation between motivational climate and self-esteem change, $F$ change $(2,212)=0.44, R^{2}$ change $=$ $.004, B_{\text {mastery }}=.10, B_{\text {ego }}=-.06, P=.65$, supporting the proposition that self-esteem change was mediated by autonomy change linked to the impact of perceived parental motivational climate.

\section{Discussion}

The two motivational theories, AGT and SDT, that provided the conceptual framework for the present study, complement one another in important ways [13, 32]. Both focus on important aspects of motivation. AGT addresses differences in conceptions of success in the form of achievement goal orientations and the motivational climates that help establish, maintain, and change them. SDT focuses on a broader set of basic psychological needs and their links to psychological well-being, with special emphasis on the relative autonomy dimension of motivational regulation. Within the AGT framework, firm empirical linkages have been established between motivational climate and achievement goal orientations, and both variables have been related to important indices of enjoyment, achievement behaviors, and well-being, including self-esteem [28, 32, 48]. SDT-inspired research has established links between motivational autonomy and psychological well-being, including self-esteem [5]. Finally, empirical relations have been demonstrated between motivational climate, achievement goal orientations, autonomy, and self-esteem [14, 17, 27, 33]. Additional linkages between the two theories have been forged through evidence that intrinsic motivation (the strongest representation of autonomous motivation) helps mediate the effects of motivational climate on indices of psychological wellbeing, including self-esteem $[14,18]$. Much of this work has been conducted within the sport environment, known to be an engaging and important setting for psychological development [49].

This study advanced previous findings in several ways. Virtually all of the research cited above has focused on the coach-initiated motivational climate, while none would deny that coaches play a central role in this environment, so also do parents, and the values they transmit both in the sport domain and in everyday life exert a strong influence on children's psychosocial development [37]. We therefore focused on the perceived parent-initiated motivational climate. Moreover, virtually all previous research has been cross-sectional in nature. Our study provides not only three replicated cross-sectional analyses but also an assessment of both autonomy and self-esteem change over time. The latter provided an opportunity to test the meditational hypothesis in a manner not previously reported.

At a cross-sectional level, results strongly supported hypothesized relations between the perceived parentinitiated motivational climate and both self-esteem and autonomy at all three measurement periods, with a mastery climate being positively related and an ego climate being negatively related to both variables. There is little existing evidence for the relation between perceived parentinitiated motivational climate and autonomy, making this an 
important finding in its own right. Moreover, in accordance with SDT, autonomy and self-esteem were positively and significantly related at all three time periods. Additionally, the longitudinal analysis revealed that a mastery motivational climate was related to positive changes in both autonomy and self-esteem and provided strong evidence that changes in autonomy mediated self-esteem changes. This finding provides additional support for previous cross-sectional evidence for a meditational role of autonomy in self-esteem enhancement $[14,18]$, but extends it by virtue of assessing change in both the outcome variable and the hypothesized mediator.

The fact that we studied global self-esteem (rather than sport-specific evaluations) is important because our findings indicate that sport-related experiences result in psychosocial effects that generalize beyond the sport domain $[24,49]$. This is not surprising, for sports are an important and engaging aspect of most children's lives. Research has shown that mean ratings of intrinsic motivation and focused attention in sports exceed those obtained for classroom activities and interactions with friends [50,51]. For parents as well, sports are a significant aspect of family life, and their influences on children often are focused on this aspect of the child's experience [49]. Therefore, it is not surprising that a core personality variable such as global self-esteem could be influenced in a domain of such high significance for many children and parents.

Although self-esteem scores changed in accordance with motivational climate over the course of the season, the mean score changes shown in Figure 2 appear quite modest. However, it is worth noting that an inspection of the distribution of self-esteem change scores revealed appreciable changes in many athletes over the 32-week sport season, as indicated in the aforementioned finding that the SD of the change scores nearly equaled the SD of the distribution of self-esteem scores at Time 1 . A decrease representing -1 SD of scores in the Time 1 distribution was exhibited by $15.3 \%$ of the athletes, whereas $11.1 \%$ of the athletes showed an increase of similar magnitude from Time 1 to Time 3 . Likewise, the stability coefficients over the three time periods indicate not only a reasonable level of stability but also the capacity for change. These findings support the contention of theorists that the late childhood-early adolescence period is one in which self-evaluations are malleable and subject to important developmental experiences $[6,8]$.

Our findings reinforce the conclusion, drawn from many previous studies, that the motivational climate established by significant others within the sport environment has important psychosocial consequences for young athletes. Not surprisingly, therefore, attempts have been made to develop coach- and parent-focused interventions designed to promote a mastery climate, such as the Mastery Approach to Coaching $[23,25,52]$ and the Mastery Approach to Parenting in Sports [53]. These empirically supported interventions (materials related to the Mastery Approach to Coaching and the Mastery Approach to Parenting in Sports interventions can be accessed at http://www.y-e-sports.com/), which communicate specific empirically based behavioral guidelines for promoting a mastery climate, have been shown to change the motivational climate in the direction of a stronger mastery orientation and to have salutary effects on outcome variables such as athletes' achievement goal orientations and performance anxiety. The future is certain to see additional attempts to utilize basic research to intervene within the youth sport environment in ways that promote positive psychosocial development in children and youth.

\section{Acknowledgments}

This paper was supported in part by Grant 1529 from the William T. Grant Foundation awarded to R. E. Smith and F. L. Smoll. The authors wish to acknowledge the input of two anonymous reviewers who contributed to the paper's clarity.

\section{References}

[1] C. H. Cooley, Human Nature and the Social Order, Scribner, New York, NY, USA, 1902.

[2] S. Epstein, "The self-concept revisited. Or a theory of a theory," The American psychologist, vol. 28, no. 5, pp. 404-416, 1973.

[3] S. Harter, "Developmental perspectives on the self-system," in Handbook of Child Psychology: Social and Personality Development, E. M. Hetherington, Ed., vol. 4, pp. 275-385, John Wiley \& Sons, New York, NY, USA, 1973.

[4] E. L. Deci and R. M. Ryan, "Human autonomy: the basis for true self-esteem," in Efficacy, Agency, and Self-Esteem, M. Kernis, Ed., pp. 31-49, Plenum, New York, NY, USA, 1995.

[5] E. L. Deci and R. M. Ryan, "The "what" and "why" of goal pursuits: human needs and the self-determination of behavior," Psychological Inquiry, vol. 11, no. 4, pp. 227-268, 2000.

[6] R. C. Wylie, The Self-Concept, vol. 2, University of Nebraska Press, Lincoln, Neb, USA, 1979.

[7] C. R. Rogers, "A theory of therapy, personality and interpersonal relationships, as developed in the client-centered framework," in Psychology: A Study of a Science, S. Koch, Ed., vol. 3, pp. 184-246, McGraw-Hill, New York, NY, USA, 1959.

[8] S. Coopersmith, The Antecedents of Self-Esteem, Freeman, San Francisco, Calif, USA, 1967.

[9] J. R. Whitehead, “A study of children's physical self-perceptions using an adapted physical self-perception profile questionnaire," Pediatric Exercise Science, vol. 7, no. 2, pp. 132-151, 1995.

[10] M. Rosenberg, Conceiving the Self, Basic Books, New York, NY, USA, 1979.

[11] W. B. Swann Jr., "To be known or to be adored? The interplay of self-enhancement and self-verification," in Handbook of Motivation and Cognition: Foundations of Social Behavior, R. M. Sorrentino and E. T. Higgins, Eds., vol. 2, pp. 408-488, Guilford Press, New York, NY, USA, 2009.

[12] G. R. Coudevylle, C. Gernigon, and K. A. Martin Ginis, "Self-esteem, self-confidence, anxiety and claimed selfhandicapping: a mediational analysis," Psychology of Sport and Exercise, vol. 12, no. 6, pp. 670-675, 2011.

[13] V. Hein and M. S. Hagger, "Global self-esteem, goal achievement orientations, and self-determined behavioural regulations in a physical education setting," Journal of Sports Sciences, vol. 25, no. 2, pp. 149-159, 2007.

[14] M. Standage and F. Gillison, "Students' motivational responses toward school physical education and their relationship to 
general self-esteem and health-related quality of life," Psychology of Sport and Exercise, vol. 8, no. 5, pp. 704-721, 2007.

[15] K. R. Fox, "The physical self and processes in self-esteem development," in The Physical Self: From Motivation to Wellbeing, K. R. Fox, Ed., pp. 111-139, Human Kinetics, Champaign, Ill, USA, 1997.

[16] J. G. Nicholls, "Achievement motivation: conceptions of ability, subjective experience, task choice, and performance," Psychological Review, vol. 91, no. 3, pp. 328-346, 1984.

[17] I. Balaguer, I. Casdllo, and J. L. Duda, "Apoyo a la autonomía, sadsfacción de las necesidades, motivación y bienestar en deportistas de competición: Un análisis de la teoría de la autodeterminación," Revista de Psicología del Deporte, vol. 17, pp. 123-139, 2008.

[18] J. López-Walle, I. Balaguer, I. Castillo, and J. Tristán, "Perceived motivational climate, self-determined motivation and self-esteem in young mexican athletes," Revista de Psicologia del Deporte, vol. 20, no. 1, pp. 209-222, 2011.

[19] C. Ames, "Classrooms: goals, structures, and student motivation," Journal of Educational Psychology, vol. 84, no. 3, pp. 261271, 1992.

[20] J. L. Duda, "Motivation in sport: the relevance of competence and achievement goals," in Handbook of Competence and Motivation, A. J. Elliot and C. S. Dweck, Eds., pp. 313-385, Guilford Press, New York, NY, USA, 2005.

[21] G. C. Roberts, "Understanding the dynamics of motivation in physical activity," in Advances in Motivation in Sport and Exercise, G. C. Roberts, Ed., pp. 1-50, Human Kinetics, Champaign, Ill, USA, 2001.

[22] D. C. Treasure, "Enhancing young people's motivation in youth sport: an achievement goal approach," in Advances in Motivation in Sport and Exercise, G. C. Roberts, Ed., pp. 79100, Human Kinetics, Champaign, Ill, USA, 2001.

[23] R. E. Smith, F. L. Smoll, and S. P. Cumming, "Effects of a motivational climate intervention for coaches on young athletes' sport performance anxiety," Journal of Sport and Exercise Psychology, vol. 29, no. 1, pp. 39-59, 2007.

[24] R. E. Smith, F. L. Smoll, and S. P. Cumming, "Motivational climate and changes in young athletes' achievement goal orientations," Motivation and Emotion, vol. 33, no. 2, pp. 173$183,2009$.

[25] F. L. Smoll, R. E. Smith, and S. P. Cumming, "Effects of a psychoeducational intervention for coaches on changes in child athletes' achievement goal orientations," Journal of Clinical Sport Psychology, vol. 1, pp. 23-46, 2007.

[26] D. J. O’Rourke, R. E. Smith, F. L. Smoll, and S. P. Cumming, "Trait anxiety in young athletes as a function of parental pressure and motivational climate: is parental pressure always harmful?" Journal of Applied Sport Psychology, vol. 23, no. 4, pp. 398-412, 2011.

[27] M. Kavussanu and G. C. Roberts, "Motivation in physical activity contexts: the relationship of perceived motivational climate to intrinsic motivation and self-efficacy," Journal of Sport and Exercise Psychology, vol. 18, no. 3, pp. 264-280, 1996.

[28] C. S. Dweck, Self-Theories and Goals: Their Role in Motivation, Personality, and Development, Taylor \& Francis, Philadelphia, $\mathrm{Pa}$, USA, 1999.

[29] M. Reinboth and J. L. Duda, "Perceived motivational climate, need satisfaction and indices of well-being in team sports: a longitudinal perspective," Psychology of Sport and Exercise, vol. 7, no. 3, pp. 269-286, 2006.

[30] D. E. Conroy and J. D. Coatsworth, "Coach training as a strategy for promoting youth social development," Sport Psychologist, vol. 20, no. 2, pp. 128-144, 2006.
[31] F. L. Smoll, R. E. Smith, N. P. Barnett, and J. J. Everett, "Enhancement of children's self-esteem through social support training for youth sport coaches," Journal of Applied Psychology, vol. 78, no. 4, pp. 602-610, 1993.

[32] J. L. Duda and D. C. Treasure, "Motivational processes and the facilitation of quality engagement in sport," in Applied Sport Psychology: Personal Growth to Peak Performance, J. M. Williams, Ed., pp. 59-80, McGraw-Hill, New York, NY, USA, 2010.

[33] L. Kipp and A. J. Amorose, "Perceived motivational climate and self-determined motivation in female high school athletes," Journal of Sport Behavior, vol. 31, pp. 108-129, 2008.

[34] L. G. Pelletier, M. S. Fortier, R. J. Vallerand, K. M. Tuson, N. M. Briere, and M. R. Blais, "Toward a new measure of intrinsic motivation, extrinsic motivation, and amotivation in sports: the sport motivation scale (SMS)," Journal of Sport and Exercise Psychology, vol. 17, no. 1, pp. 35-53, 1995.

[35] M. M. Georgiadis, S. J. H. Biddle, and N. L. D. Chatzisarantis, "The mediating role of self-determination in the relationship between goal orientations and physical self-worth in Greek exercisers," European Journal of Sport Science, vol. 1, no. 5, pp. $1-9,2001$.

[36] M. L. Babkes and M. R. Weiss, "Parental influence on children's cognitive and affective responses to competitive soccer participation," Pediatric Exercise Science, vol. 11, no. 1, pp. 44-62, 1999.

[37] T. S. Horn and J. L. Horn, "Family influences on children's sport and physical activity participation, behavior, and psychosocial responses," in Handbook of Sports Psychology, G. G. Tenenbaum and R. C. Eklund, Eds., pp. 685-711, John Wiley \& Sons, Hoboken, NJ, USA, 2007.

[38] E. M. Pomerantz and R. A. Thompson, "Parents' role in children's personality development: the psychological resource principle," in Handbook of Personality: Theory and Research, P. John, R. W. Robins, and L. A. Pervin, Eds., pp. 351-374, Guilford Press, New York, NY, USA, 2007.

[39] S. A. White, "Adolescent goal profiles, perceptions of the parent-initiated motivational climate, and competitive trait anxiety," Sport Psychologist, vol. 12, no. 1, pp. 16-28, 1998.

[40] J. L. Duda and J. Whitehead, "Measurement of goal perspectives in the physical domain," in Advances in Sport and Exercise Psychology Measurement, J. L. Duda, Ed., pp. 21-48, Fitness Information Technology, Morgantown, WVa, USA, 1998.

[41] R. E. Smith and F. L. Smoll, "Self-esteem and children's reactions to youth sport coaching behaviors: a field study of self-enhancement processes," Developmental Psychology, vol. 26, no. 6, pp. 987-993, 1990.

[42] V. C. Crandall, V. J. Crandall, and W. Katkovsky, "A children's social desirability questionnaire," Journal of Consulting Psychology, vol. 29, no. 1, pp. 27-36, 1965.

[43] M. Gagné, R. M. Ryan, and K. Bargmann, "Autonomy support and need satisfaction in the motivation and well-being of gymnasts," Journal of Applied Sport Psychology, vol. 15, no. 4, pp. 372-390, 2003.

[44] W. S. Grolnick and R. M. Ryan, "Autonomy in children's learning: an experimental and individual difference investigation," Journal of Personality and Social Psychology, vol. 52, no. 5, pp. 890-898, 1987.

[45] J. B. Cohen and P. Cohen, Applied Multiple Regression/Correlation Analysis for the Behavioral Sciences, Lawrence Erlbaum Associates, Hillsdale, NJ, USA, 1983.

[46] L. S. Aiken and S. G. West, Multiple Regression: Testing and Interpreting Interactions, Sage, Newbury Park, Calif, USA, 1991. 
[47] R. M. Baron and D. A. Kenny, "The moderator-mediator variable distinction in social psychological research. Conceptual, strategic, and statistical considerations," Journal of Personality and Social Psychology, vol. 51, no. 6, pp. 1173-1182, 1986.

[48] S. McArdle and J. K. Duda, "Implications of the motivational climate in youth sports," in Children and Youth in Sport: A Biopsychosocial Perspective, F. L. Smoll and R. E. Smith, Eds., pp. 409-434, Kendall/Hunt, Dubuque, Iowa, USA, 2002.

[49] M. R. Weiss, Developmental Sport and Exercise Psychology: A Lifespan Perspective, Fitness Information Technology, Morgantown, WVa, USA, 2002.

[50] M. Csikszentmihalyi and R. W. Larson, Being Adolescent, Basic Books, New York, NY, USA, 1984.

[51] R. W. Larson and D. Kleiber, "Daily experience of adolescents," in Handbook of Clinical Research and Practice With Adolescents, P. Tolan and B. Cohler, Eds., pp. 125-145, John Wiley \& Sons, New York, NY, USA, 1993.

[52] R. E. Smith and F. L. Smoll, "Cognitive-behavioral coach training: a translational approach to theory, research, and intervention," in Behavioral Sport Psychology: Evidence-Based Approaches to Performance Enhancement, J. K. Luiselli and D. D. Reed, Eds., pp. 227-248, Springer, New York, NY, USA, 2011.

[53] F. L. Smoll, R. E. Smith, and S. P. Cumming, "Effects of coach and parent training on performance anxiety in young athletes: a systemic approach," Journal of Youth Development, vol. 2, Article ID 0701FA002, 2007, http://nae4a.memberclicks.net/ assets/documents/JYD_070201_final.pdf. 


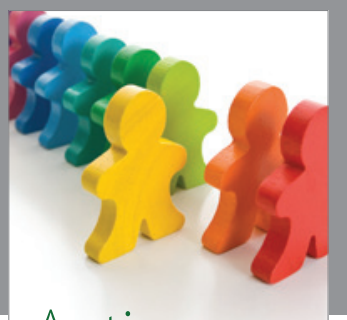

Autism

Research and Treatment
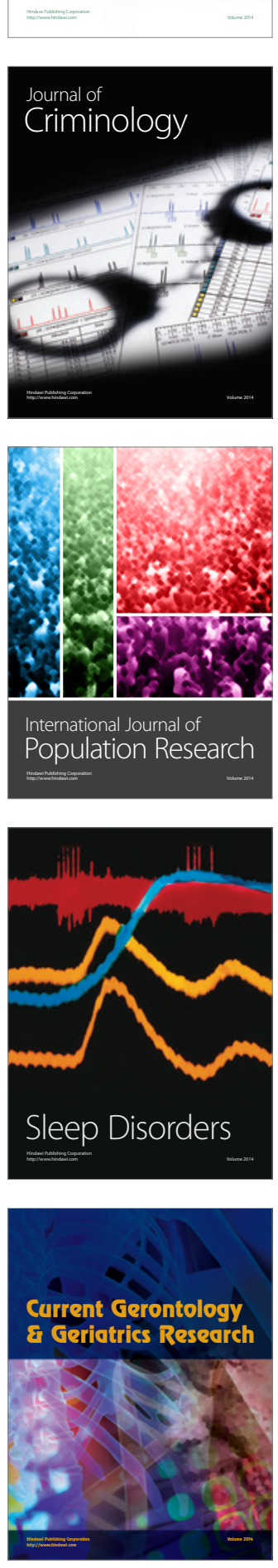
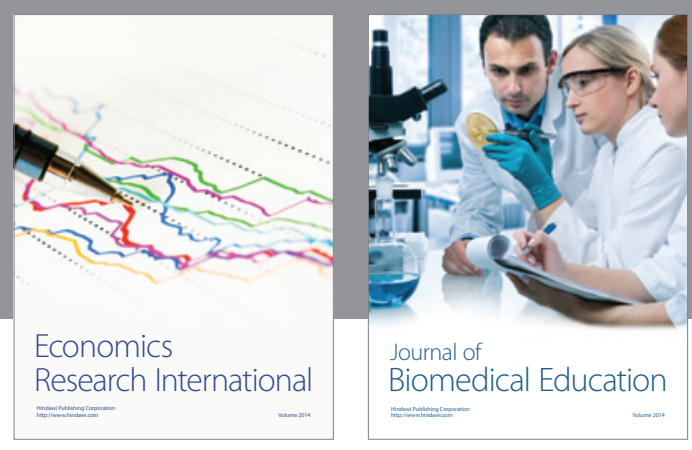

Journal of

Biomedical Education

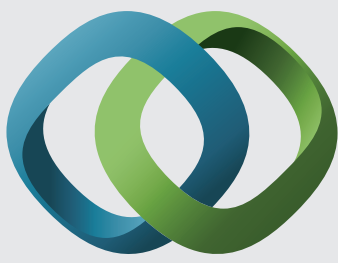

\section{Hindawi}

Submit your manuscripts at

http://www.hindawi.com
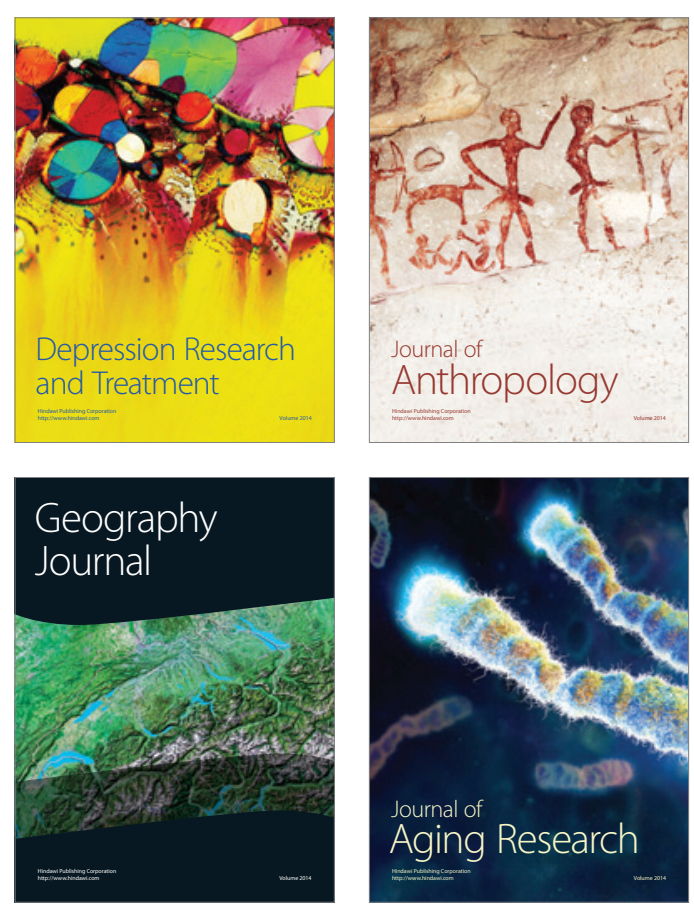

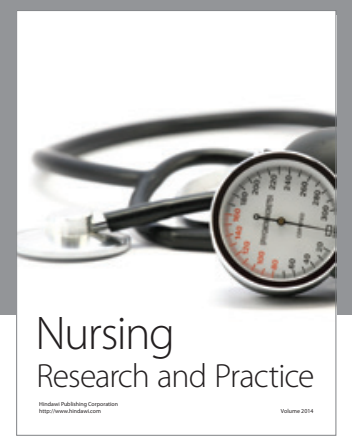

Nursing

Research and Practice

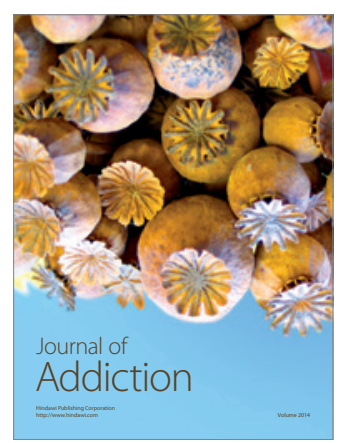

Child Development

Research

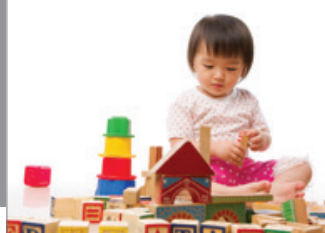

迥
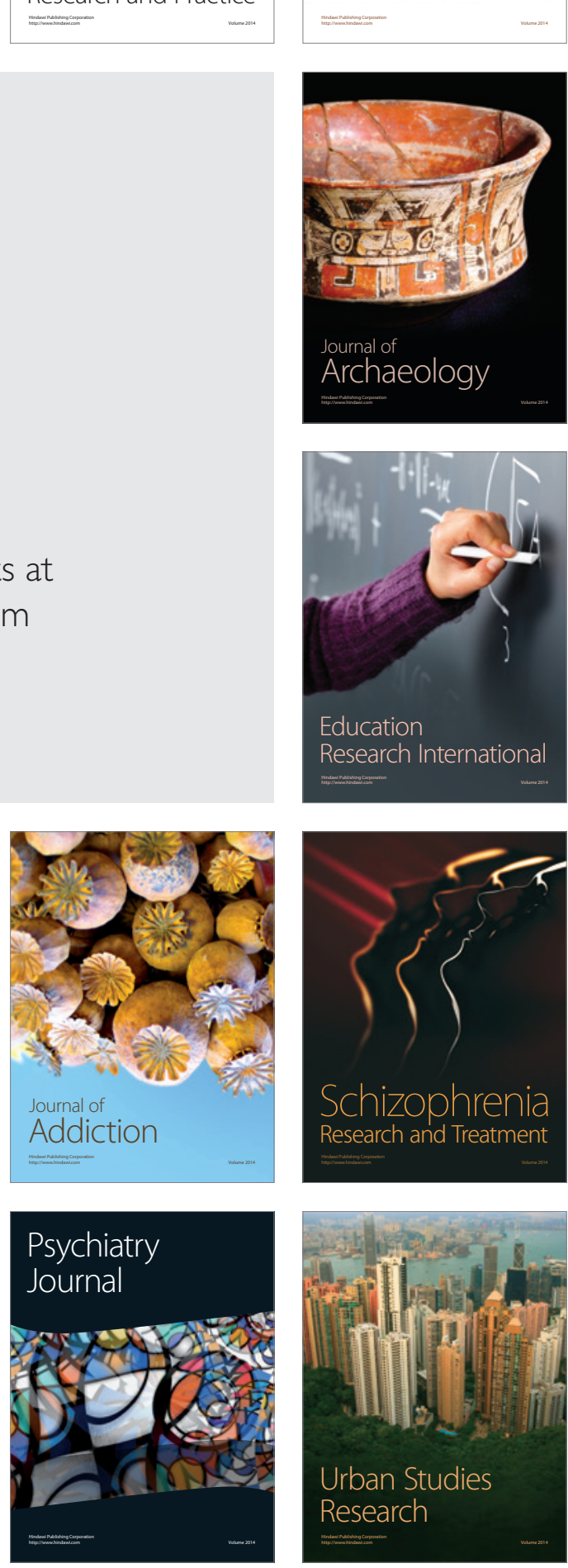